http://ejtr.vumk.eu

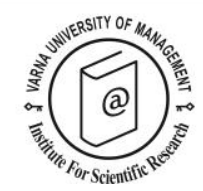

\title{
Residents' apathy and its influence on tourism development
}

\author{
Vahid Ghasemi ${ }^{1}$
}

Received: 10/04/2018

\begin{abstract}
${ }^{1}$ Ph.D. in Economics and Business Department of Economics and Business, University of Cagliari, Italy Via San Giorgio, 12, 09124 Cagliari (CA) - Italy, Phone: + (39) 348805 2982. E-mail: vghasemi@unica.it

Coordinating editor: Faizan Ali
\end{abstract}

Supervisors: Prof. Giacomo Del Chiappa and Prof. Antonia Correia

Institution awarding the Ph. D. Degree: University of Cagliari, Italy

Date of defence: 26/03/2018

Citation: Ghasemi, V. (2019) Residents' apathy and its influence on tourism development. Doctoral Dissertation Summary. European Journal of Tourism Research 22, pp. 193-197

\section{Goal and objectives of the dissertation \\ Goal}

The Thesis aims at deepening the academic knowledge of apathy as barrier (Tosun, 2000) and its influence upon tourism development. Although apathy has been cited as a leading cultural barrier that prevents residents from playing an active role in tourism development, current academic literature has not yet defined this concept, its dimensions, and how they affect resident support of tourism. To achieve these aims, this research relying on three main "disciplines" which deal with, define and interpret the concept of apathy (namely psychology, socio-politics and environment), an extensive and multidisciplinary literature review is presented and discussed. Based on this literature review, the theoretical part ends by suggesting three main dimensions shaping residents' apathy (namely: lack of interest, lack of initiative and environmental-based apathy); further, it proposes items and scales to be used to measure it. Following the results of this literature review, this research aims at investigating whether, and the extent to which, residents' apathy is able to influence tourism development. To reach this aim, both resident-based and tourist-based perspective is adopted.

\section{Objectives}

This study tests a conceptual model investigating the extent to which each of the identified dimensions of residents' apathy is able to negatively affect residents' willingness to support tourism development in their community, and to sustain the destination brand by talking positively about their destination and recommending it to others,

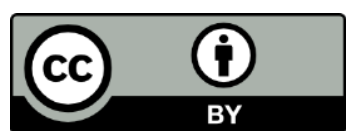

This work is licensed under the Creative Commons Attribution 4.0 International (CC BY 4.0). To view a copy of this license, visit https://creativecommons.org/licenses/by/4.0/ 


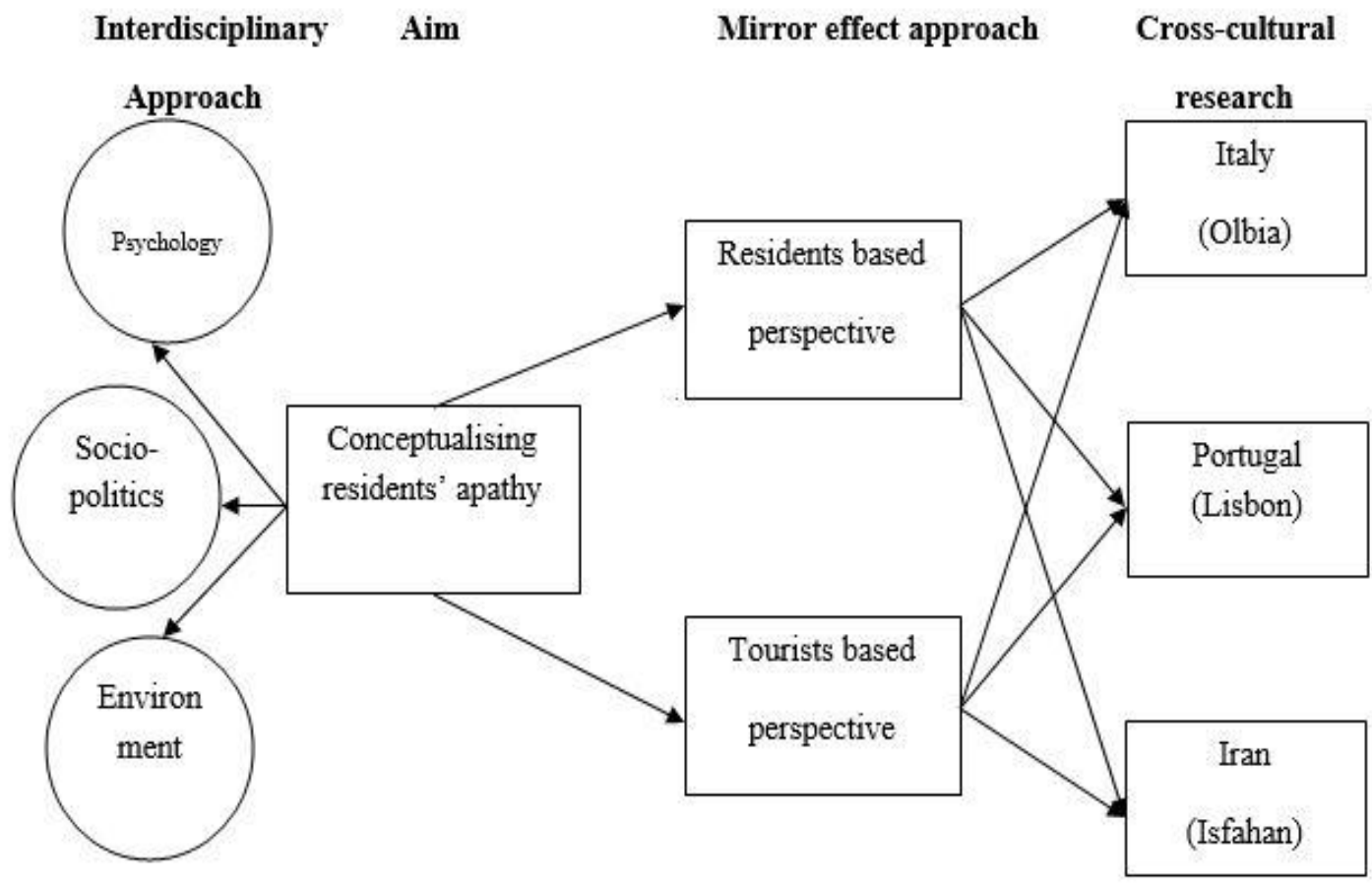

Figure 1. The scope and realm of the Thesis

both offline (traditional word-of-mouth: WOM) and online (electronic word-of-mouth: eWOM). To achieve this aim, the study applies an analysis to three convenience data samples collected in three different tourism destinations (i.e. Olbia, Italy; Lisbon, Portugal; Isfahan, Iran) (see figure 1).

Additionally, this research tests a conceptual model investigating the effects, as perceived by visitors, that residents' apathy exerts on perceptions of service quality, the extent to which residents are seen to support the tourism phenomenon, and visitors' behavioural intentions and residents' support. According to the existing literature (e.g. Del Chiappa \& Bregoli, 2012; Sautter \& Leisen, 1999), our second conceptual model relies on the idea that residents can be considered as "frontline employees", able to significantly shape tourists' perceptions of quality and their behavioural intentions via offline and online word-of-mouth. To achieve this aim, the study applies an analysis to three samples based on convenience sampling data collected in the same tourism destinations of first empirical Chapter.

\section{Methodology}

In order to answer the raised questions, a preliminary literature review was carried out to identify the academic disciplines in which studies have been devoted to defining, interpreting and analysing apathy (see the figure 1). Hence, three main disciplines were identified as the basis of our theoretical understanding of the concept under investigation: namely, psychology, sociopolitics and environment.

Based on this literature review, a list of potential items and scales for measuring apathy were identified and used to frame the two survey instruments that constituted the basis of the two empirical studies testing the two conceptual models: namely the residentbased and the tourist-based. 


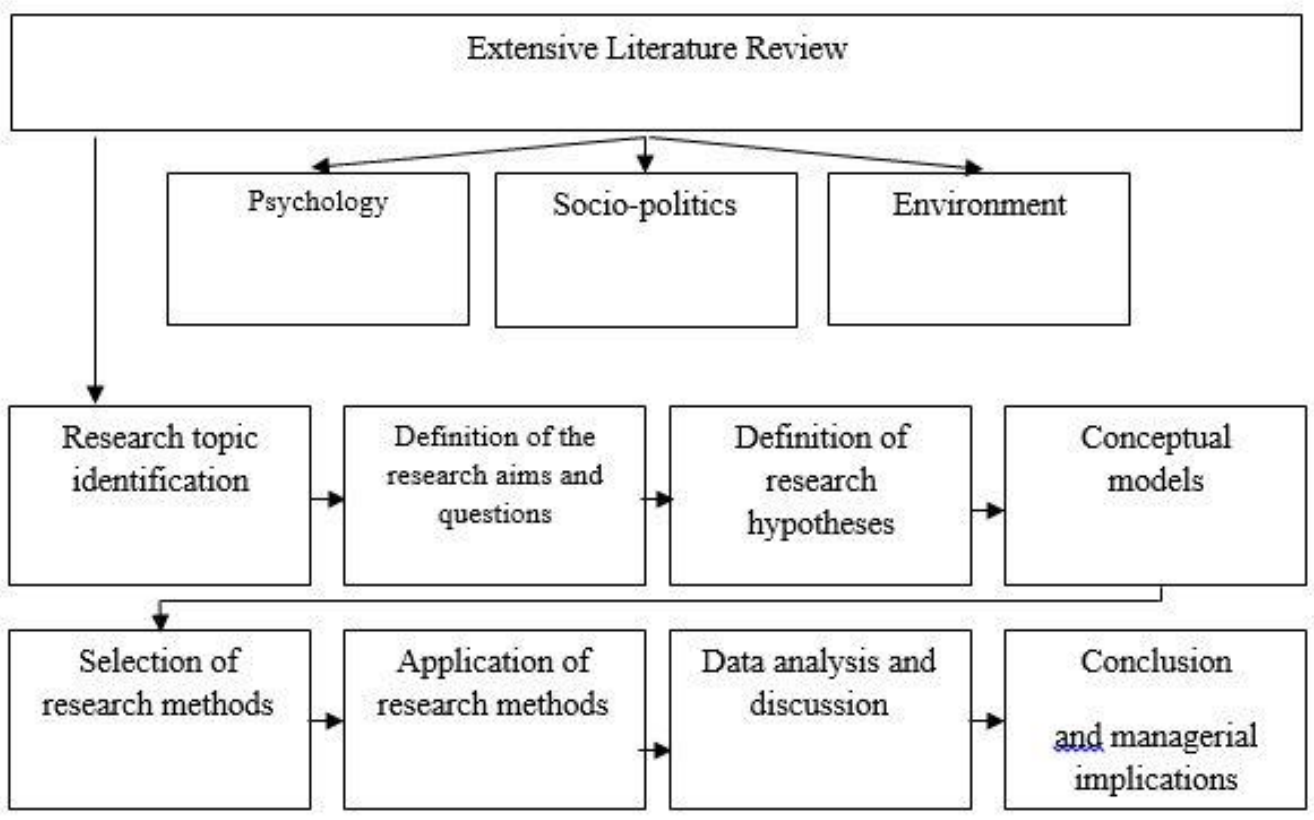

Figure 2. Proposed Research Methodology

For the purposes of this PhD dissertation, two specific survey instruments (based on the existing literature) were developed, one adopting a resident-based perspective and one adopting a tourist-based perspective. For the resident-based perspective, a total of 303 completed questionnaires were obtained from Portugal, 471 from Iran and 560 from Olbia. Overall, 1334 completed resident questionnaires were obtained which were suitable for the purpose of analysis. As far as the tourist-bases study is concerned, overall, 947 complete questionnaires were obtained, of which 309 were collected in Lisbon, 338 in Isfahan and 300 in Olbia. All the samples obtained need to be considered as convenience samples.

Then, Structural Equation Modelling (SEM) as statistical approach was applied for the purpose of this study.

\section{Results}

This research investigated the concept of apathy by relying on three different disciplines (psychology, socio-politics and environmental-based literature) that have been devoted to discussions of the meaning of apathy as a general concept. This made it possible to root the concept theoretically and to identify its main dimensions when contextualised in tourism settings. Hence, this knowledge was used to frame the items and the scale to be used to measure apathy and its influence on tourism development.

The study also proposed and tested two different conceptual frameworks. Both conceptual models were tested by using data collected in three different tourism destinations, namely Lisbon, which is the capital city of Portugal; Isfahan, known as the capital of tourism in Iran; and Olbia, a municipality located in the north-east of Sardinia (Italy).

According to the findings from residents' perspective, apathy has been proved to be made up of three latent constructs; lack of interest, lack of initiative, and environmentalbased apathy. The data also supports the idea that residents' apathy negatively influences the brand ambassadorship behaviour of residents. 
According to the results from tourist perspective, residents' apathy as perceived by tourists has been proven to consist of four latent constructs: lack of interest, lack of initiative, alienation and environmental-based apathy. Furthermore, the tourists' perception of residents' apathy influences negatively the perceived residents' support of tourism.

Results strongly suggests the need to make residents fully conscious about the extent to which it is important to adopt a proactive role toward tourists and to welcome them warmly to the destination.

\section{Theoretical conclusions}

From a theoretical point of view, this study is the first attempting to analyse deeply the concept of residents' apathy in tourism settings, to identify its main dimensions and to propose items and scales to be used to measure it. Second, it proves that residents' apathy exerts a significant influence over residents' support of tourism and their willingness to support brand ambassadorship behaviours offline and online. Further, it proves that residents' apathy significantly affects the service quality that tourists might perceive during host-guest interactions, which, in turn, significantly affects tourists' offline and online brand ambassadorship behaviour.

\section{Practical application of the dissertation}

Overall, this study's findings suggest that destination marketers and policy makers should plan and implement significant internal marketing operations with the aim of empowering residents, to let them feel themselves to be powerful and active actors in the tourism phenomenon in their community (Del Chiappa, Atzeni, \& Ghasemi, 2016). Particularly, they should be 'trained' to understand that their behaviour during hostguest interactions shapes tourists' perceived service quality and influences the likelihood that tourists will positively talk about the destination, both online and offline. In this way, residents could be more aware and conscious about the consequences of their behaviour and, thus, more prone to change and improve their behaviour, with the aim of further improving their ability to welcome visitors in their community positively. Recent research on the topic of the smart tourism destination and e-democracy (Del Chiappa \& Baggio, 2015; Presenza, Micera, Splendiani \& Del Chiappa, 2014; Sigala \& Marinidis, 2012) suggests that information and communication technology (ICT) and social media (such as Facebook and Instagram) could be used as internal marketing tools to empower the local community and to allow residents to participate in tourism planning. This, coupled with the fact that this study's findings show that active (non-apathetic) residents would be willing to talk positively about their place to other individuals, especially through online platforms, suggests that destination marketers should do their best to eliminate any digital divides in their community.

\section{Content of the dissertation}

\section{Abstract of Chapter 1}

This study analyses the concept of resident apathy toward tourism and defines its underpinnings and influence on resident attitudes toward the development of tourism. It presents and discusses the existing literature devoted to community participation, paying particular attention to those who refer to and describe a "passive" attitude and resident behaviour toward tourism development. Adopting an interdisciplinary approach, the Chapter discusses the concept of apathy. It provides academicians and practitioners with information for interpreting and analysing resident apathy and for understanding the main dimensions that shape it. Meanwhile, the study suggests action and operations (e.g. internal marketing and branding) that are needed to increasing resident interest in and commitment toward the tourism phenomenon in their area and to increase their support for tourism development. Ideas for future research include finding conceptual frameworks to be tested empirically through quantitative study.

\section{Abstract of Chapter 2 \\ Apathy has been considered as a barrier in community integration and participation in tourism planning. The current academic community urges us to have a deeper}


understanding about what effectively drives residents to be apathetic towards the tourism phenomenon; in addition to contributing to the current body of knowledge, this would be extremely useful for policymakers and destination marketers attempting to reduce/eliminate apathy. The aim of this study is to identify the underlying dimensions of apathy and to test the extent to which they influence residents' support for tourism development and their brand ambassadorship behaviour. For the purposes of this study, three tourism destinations were identified, namely: Olbia (Sardinia, Italy), Lisbon (Portugal) and Isfahan (Iran) and a Structural Equation Modelling analysis was applied. Based on our results, residents' apathy is mostly conceptualised by lack of interest, lack of initiative and environmental-based apathy. Furthermore, the findings highlight that apathy (and its dimensions) negatively influences residents' support of tourism and their brand ambassadorship behaviour. From a theoretical point of view, the paper conceptualises residents' apathy, proposes a conceptual model and tests it through SEM applied in three different tourism destinations, thus highlighting differences among the research settings. Managerial implications are discussed as well as the main limitations, then suggestions for further research are given.

\section{Abstract of Chapter 3}

Residents' apathy has been considered a cultural barrier to community integration and participation and also a factor that might negatively affect the quality of the host-guest interaction. Despite this, to best of our knowledge the influence that residents' apathy (as perceived by visitors) can exert on perceived service quality, satisfaction and behavioural intentions of tourists is theorized and sometimes considered. This study aims to contribute to filling this gap by proposing a theoretical model and testing it in three different destinations, namely, Lisbon (Portugal), Isfahan (Iran) and Olbia (Sardinia, Italy). This study contributes to the current body of knowledge by proposing and testing a conceptual model that aims to analyse how residents' apathy (i.e. lack of interest, lack of initiative, alienation and environmental-based apathy), as perceived by tourists, affects the host-guest interaction and, more specifically, the perceived service quality and the visitors' behavioural intentions. Managerial implications are discussed as well as the main limitations, then suggestions for further research are provided.

\section{References:}

Del Chiappa, G., \& Baggio, R. (2015). Knowledge transfer in smart tourism destinations: Analyzing the effects of a network structure. Journal of Destination Marketing \& Management, 4(3), 145-150.

Del Chiappa, G., and Bregoli, I. (2012). Destination branding development: linking together supply-side and demand-side perspectives. In Tsiotsou, R. H. and Goldsmith, R. E. (Eds). Strategic Marketing in Tourism Services. Bingley: Emerald.

Del Chiappa, G., Atzeni, M., \& Ghasemi, V. (2016). Community-based collaborative tourism planning in islands: A cluster analysis in the context of Costa Smeralda. Journal of Destination Marketing \& Management, 8, 41-48.

Presenza, A., Micera, R., Splendiani, S., \& Del Chiappa, G. (2014). Stakeholder einvolvement and participatory tourism planning: analysis of an Italian case study. International Journal of KnowledgeBased Development, 8, 5(3), 311-328.

Sautter, E. T., \& Leisen, B. (1999). Managing stakeholders, a tourism planning model. Annals of tourism research, 26(2), 312-328.

Sigala, M., \& Marinidis, D. (2012). Edemocracy and web 2.0: A framework enabling DMOs to engage stakeholders in collaborative destination management. Tourism Analysis, 17(2), 105-120.

Tosun, C. (2000). Limits to community participation in the tourism development process in developing countries. Tourism Management, 21(6), 613-633. 